\title{
Cultura Cultura
}

Revistade historia e Teria das ldeais $\quad$ Revista de História e Teoria das Ideias

Vol. 23 | 2006

Ideia(s) de Tempo(s)

\section{A espuma do tempo}

Time Foam

\section{Adriano Moreira}

\section{OpenEdition}

\section{Journals}

\section{Edição electrónica}

URL: http://journals.openedition.org/cultura/1271

DOI: 10.4000/cultura.1271

ISSN: 2183-2021

\section{Editora}

Centro de História da Cultura

\section{Edição impressa}

Data de publição: 1 Janeiro 2006

Paginação: 9-14

ISSN: 0870-4546

\section{Refêrencia eletrónica}

Adriano Moreira, «A espuma do tempo », Cultura [Online], Vol. 23 | 2006, posto online no dia 14

fevereiro 2014, consultado a 20 abril 2019. URL : http://journals.openedition.org/cultura/1271 ; DOI :

$10.4000 /$ cultura. 1271

Este documento foi criado de forma automática no dia 20 Abril 2019

(c) CHAM - Centro de Humanidades / Centre for the Humanities 


\title{
A espuma do tempo
}

\author{
Time Foam
}

Adriano Moreira

1 Quando a Europa atingiu a estabilidade suficiente que pode ser chamada de vida habitual, com cidades capitais a dispensar as Cortes de serem itinerantes, salvo uns intervalos frequentes das guerras internas e internacionais, o estatuto dos Embaixadores enriqueceu-se de prestígio social, com expressão na residência que honrasse o país de origem, circulando íntimos pelas elites políticas, militares, e culturais, observando, pensando, e transmitindo as conclusões, as prevenções, e os conselhos aos respectivos governos.

2 A tradicional centralização da direcção da política externa, acoplando a responsabilidade militar, fazia dos embaixadores os olhos do Rei, e muitos deixaram textos de presença indispensável no estudo e meditação da evolução da conjuntura internacional, das variações do conceito estratégico nacional ao longo dos tempos, dos pontos fortes e fracos do desempenho do Estado perante a incerta tabela dos acidentes e desafios da política.

3 A complexidade crescente da rede mundial de dependências, e o tempo acelerado da mudança, ultrapassaram as capacidades, as rotinas, e a criatividade dessas estruturas, que se tinham arquitectado em tempo demorado, os Estados perderam de regra a eficácia do modelo da centralidade da direç̧ão, e, sem grande diferença qualitativa entre poderosos e pequenos, multiplicam, por todas as áreas das competências que guardam, os centros de intervenção que se articulam em redes internacionais, sem que isso tenha necessária réplica em redes internas que mantenham a corrente da informação entre todos.

4 Na defesa, nas finanças, na economia, na cultura, na ciência, na educação, nas instituições financeiras do Estado, as responsabilidades, que exigem percepção e prospectiva, multiplicam as linhas de acção, as quais se cruzam com homólogas emergências vindas da sociedade civil, também esta a multiplicar as redes privativas que traçam os modelos transfronteiriços da vida contratualizada, redes que se enlaçam em centros de diálogo, de exigência, e de acomodação, tendo por interlocutor o surpreendido Estado, por vezes o reverente Estado, algumas vezes o inferiorizado Estado. 
5 Por tudo, não apenas o aparelho diplomático secular tem dificuldades sérias em assegurar métodos e capacidades de controlo global, com embaraços que nascem, entre mais causas, da deficiência de modelações jurídicas, de práticas que criam uma espécie de soft low que embaraça a racionalidade, da concorrência de uma variedade de interventores políticos com reverências hierarquizadas, tudo dando por vezes a impressão de que a multiplicação e velocidade das intervenções se transforma numa espuma dos tempos que a natureza das coisas vai pontuando de emergências, que sugerem a responsabilidade de um Deus desconhecido.

6 Os perigos do holocausto nuclear foram reconhecidos de longe, os tratados de salvaguarda multiplicaram-se, as diplomacias afadigaram-se, os serviços de informação foram sofisticados, as instâncias internacionais reuniram colectivos vigiados pelos meios de comunicação mundial, e subitamente as novas potências nucleares desvendam-se, as movimentações diplomáticas ganham novo ímpeto, a espuma dos tempos avoluma-se, e a natureza das coisas faz saber a dimensão da perigosa realidade que se foi estruturando. Entretanto, os Chefes das diplomacias, incluindo os dos Estados mais poderosos, vão de capital em capital, de conferência em conferência, de declaração em declaração, circulando pelo globalismo cujas debilidades não os responsabilizam apenas porque as não previram, a correr e a pensar, por esta criticável ordem, de acordo com a leitura imposta pela corrente ininterrupta de desmentidos, de correcções, de aditamentos. Martin Luther King sintetizou: "A cobardia pergunta - é seguro? O oportunismo pergunta - é político? A vaidade pergunta - é popular? Mas a consciência pergunta - está certo?" (in Madeleine Albright, Os poderosos e o Todo-Poderoso, Lisboa, pág. 63).

7 Pregadores da urgência da verdade no exercício da política como foi Ana Arendt, e da importância do diálogo como sustentam todos, dificilmente podem conciliar-se com o panorama desta época que se pretende que seja da informação e do saber, longe também da sabedoria que invocaram.

8 Inverter o ritmo, isto é, regressar ao modelo de pensar antes de correr, exige uma profunda remodelação dos aparelhos diplomáticos, de modo que a coordenação volte a ser um valor reconhecido, não apenas pela filosofia de governo de cada Estado, também pela dos grandes espaços em que os Estados se articulam.

9 No caso de ser possível, sem agravo, usar um exemplo, com modéstia académica, talvez exija exame e meditação o exercício de diplomacia internacional de que é agente o responsável pela política externa e de segurança da União Europeia, franciscanamente sorridente em todas as circunstâncias, em nome de uma realidade virtual, agitando a espuma do tempo, enquanto a natureza das coisas, que há séculos bateu à porta de Bizâncio, que há menos séculos bateu à porta de Viena, bate agora a todas as portas do Ocidente.

10 Nesta circunstância, evidenciou-se outra novidade desafiante do método diplomático. Trata-se de a comunicação social antecipar a formação da opinião pública antes que os governos recebam a informação diplomática necessária e possam intervir, evitando recorrer ao método da teatrologia, ao exagero da mentira real, pondo em causa a credibilidade diplomática.

11 Em 1977, o professor Schwartzemberg publicou, obtendo grande êxito, um livro intitulado L'État Spectacle no qual advertia que o discurso político tendia para ser substituído pelo que chamou a teatrologia, recorrendo a conceitos importados dessa arte para dar consistência à demonstração. A observação da natureza virtual das lideranças que 
surpreendia alicerçadas nessa mediatização, parece ter sido o que o encaminhou para, duas décadas mais tarde (1998), de parceria com Roger Gérard, publicar La politique Mensonge.

12 Alguns factos da conjuntura desta entrada do milénio interpelam no sentido de ter presente a advertência que aquelas indagações apoiaram, e avaliar as consequências de a teatrologia política ter violado severamente a tolerância possível para a mentira real que os analistas dificilmente consideram ser evitável na luta pelo poder político e seu exercício, fazendo em todo o caso apelo à prudência. Um facto agravado pela circunstância de a opinião pública se encontrar por vezes alienada a sistemas de comunicação vinculados a interesses dominantes.

13 É possível que o exercício da primeira Guerra do Golfo tenha mostrado alguma realidade do que se passava no terreno, mas a audiência foi subordinada à teatrologia adoptada. A segunda Guerra do Golfo cada vez mais se desvenda como apoiada num exercício retórico que tratou com descaso a recomendada prudência dos pragmáticos de não exceder a mentira razoável, um excesso neste caso denunciado pelas consequências, tudo seguido pelo descrédito de lideranças, abalo de solidariedades, perdas do capital de esperanças. Mas a erosão da governança confiável aprofunda-se quando a teatrologia esconde, sob o véu da realidade virtual, a debilidade efectiva, quer da falta de projecto, quer de uma clara concepção do mundo e da vida a defender e consolidar, quer de uma consistente liderança.

14 A divulgada tese do conflito de culturas teve uma resposta, baseada na razão, no sentido de procurar pelo diálogo instaurar o respeito recíproco, a compreensão pelo saber repartido, a tolerância pelas diferenças que não tendem à ruptura da paz. A turbulência causada pelo discurso académico que Bento XVI fez na Universidade de Ratisbona, abordando com notável qualidade a questão do encontro e debate entre as áreas culturais nesta conjuntura de liberdade internacional sem precedente, com acento tónico nas relações entre a razão e a fé, aconselha a alargar a meditação sobre os limites da tolerância, que não podem ser definidos pelo Estado sem apoio numa sólida diplomacia.

15 A liberdade referida resulta do facto de o ponto final colocado no império euromundista ter libertado a voz própria, na vida internacional, de todas as áreas culturais pelas quais antes falavam os poderes coloniais ou dominantes. O capital de queixas não pode ser ignorado, mas o projecto da paz exige que ele seja fonte de sabedoria e não tolera que seja uma inspiração de retaliação. Talvez a citação que relembrou o Imperador Manuel II Paleólogo, esquecido na memória europeia, exija uma reflexão que tem primeiro que ver com a realidade interna dos ocidentais, e só depois com os excessos demagógicos de lideranças muçulmanas que apelam à violência sem relerem os textos. Em primeiro lugar tendo presente que era em conjuntura de desastre que o Imperador se pronunciava, e o peso das suas palavras respondia à agressão armada que finalmente tomaria Constantinopola e liquidaria o império. Nada que não inspirasse Erasmo quando igual alarme chegava às portas de Viena. Nada que faça esquecer que já em 1192, Saladino e Ricardo, ao negociarem colocar um ponto final na $3^{\mathrm{a}}$ Cruzada, afirmaram: Ricardo que a Jerusalém não podem os cristãos renunciar, ainda que devam morrer até ao último soldado; Saladino contrapondo que para eles ainda era mais irrenunciável porque ali se juntariam no Dia do Julgamento. Como nota Albright, "oitocentos anos mais tarde, também as nossas negociações sofreram um colapso".

16 O respeito pelos Livros Santos não apoia tolerância para a manipulação dos valores religiosos a favor de projectos estratégicos de poder, quer se trate de Constantinopla, 
quer de Viena, quer dos ocidentais, um facto evidente no exercício do terrorismo global, e que, repita-se, não consente tolerância. Neste ponto, é em primeiro lugar para o comportamento das lideranças ocidentais que portanto é necessário medir a tolerância adoptada mesmo voltando a esquecer o Imperador, mas relendo as exortações de Erasmo contra a anarquia das vontades europeias então perdidas em debates internos que apoiavam o descaso irresponsável para as violentas ameaças externas em progresso. Mas também não é recomendável tolerância para a teatrologia que adensa a espuma de cada tempo, e alastra o deserto real.

17 Admitir que um discurso possa ter como resposta desencadear movimentos de massas que desrespeitam templos, que apelam ao combate, que apoiam o recurso a repetições do 11 de Setembro, não tem fundamento em Livros Santos, tem que ver com a natureza internacional do Estado que os consente, ou que os apoia, ou que os inspira. Estamos então em face de um perigo que exige prudência, mas que não consente descaso. Exige que a teatrologia dos discursos não diminua a visibilidade dos desafios, tecendo um véu de ignorância sobre as exortações que de longe convidam a meditar sobre a decadência da Europa. É grave tomar os moinhos por gigantes; é pior tomar os gigantes por moinhos. $O$ apoio das políticas consistentes depende muito da capacidade diplomática de conseguir chegar, atempadamente, àquilo que foi chamado - o deserto do real.

E assim chegamos a uma das mais desafiantes circunstâncias que interpelam a capacidade diplomática, a qual se traduz no que chamaria o véu da ignorância que, como resultante em cuja génese estão muitas das referências mencionadas, se interpõe entre os cidadãos, os eleitorados, a vontade política dos cidadãos e os governos.

Para tornar a situação internacional ainda mais preocupante, do ponto de vista da paz e segurança, e do que resulta dos factos que podem ser dados por fiáveis, cresce a preocupação sobre a cortina de ignorância que vai sendo tecida em mais de um domínio das relações internacionais, e que corta o acesso das populações interessadas ao conhecimento da realidade. Não se trata da área reservada ao segredo de Estado, uma temática subordinada à disciplina do Estado de Direito, que introduz limitações claras. Mas área essa também submetida ao assédio dos meios de comunicação social de variadas sedes, orientações, interesses e dependências, criando frequentemente equívocos que desafiam a distinção entre o reservado, a dimensão violada, e sobretudo a área apenas presumida mas divulgada pela curiosidade legítima ou abusiva apoiada pela colheita.

Trata-se neste ponto de uma fragilidade agravada pela frequência com que a mentira real dos clássicos é abusada pelos poderes políticos, uma prática que inevitavelmente excita as referidas práticas do assédio à reserva governativa, e parece levar a uma subjacente e paliativa doutrina de equilíbrio e legitimação dos enganos. A frequência e ritmo dos desmentidos, correcções, reinterpretações, envolventes do caudal de notícias relacionadas com os mais desafiantes conflitos de projectos, de interesses, e de comportamentos dos governos ou dos seus representantes, não pode deixar de contribuir para debilitar a segurança da opinião pública no sentido de orientar os seus apoios ou recusas em relação às políticas seguidas ou propostas pelos respectivos governos ou instâncias internacionais.

21 Nos conflitos armados que fazem parte da herança deixada pelo século XX, foi-se tornando longa a lista de profissionais dos meios de comunicação que foram sacrificados na árdua tarefa de surpreender o real, e darem assim um testemunho confiável do processo em que, pela maior parte, as populações são mais destinatárias dos efeitos do que participantes nas causas. E todavia o sacrifício torna-se mais angustiante sempre que 
os factos posteriores mostram, mais incidentalmente do que por contrição, que uma parte do real foi subtraída à observação pela eficiência da teatrologia em exercício. Uma teatrologia que vai acompanhada do perigo de analistas e comentadores não terem sempre a capacidade de serem bem-vindos ao mundo do real, frustrando-se o objectivo de ajudar a iluminar, racionalizar, tornar consistente a visão pública dos complexos processos que se cruzam e tecem um emaranhado de dependências. Fazendo um balanço da longa vida, escreveu recentemente Madeleine Albright: "À medida que vou envelhecendo, lembro-me cada vez com mais frequência de um bom católico - um amigo de um amigo - cujo epitáfio preferido rezava assim: "Deixo o mundo como nele entrei: confuso".

As coisas atingem um pico extremo quando os próprios serviços de informação estaduais que, antes de visarem apoiar uma opinião cívica esclarecida, têm por dever primeiro ajudar os governos a serem esclarecidos, são envolvidos na dúvida pública de saber se informam com aceitável consistência, se teve consistência a descodificação feita pelos governos, se afeiçoaram os fundamentos usados pela mentira real para decidir, se esta abusivamente ignorou ou afeiçoou as informações recebidas. A situação gravíssima do Médio Oriente, e as sequelas que se multiplicam por outras geografias, fornecem inquietantes exemplos de todos estes riscos, que não podem deixar de convocar as atenções para um imperativo convite de regresso ao deserto do real, usando, sem grande abuso de sentido, um apelo de variadas origens. Porque o abuso da teatrologia no processo político contribui excessivamente para que, talvez por efeito de uma lei de reflexividade, um véu de ignorância envolva, não apenas os eleitorados, mas também decisores, nas áreas mais inquietantes da paz e segurança indivisíveis.

É o que se passa com a proliferação das armas atómicas, que subitamente aflora ameaçadora em vários lugares, sendo por vezes dificil concluir sobre a relação do anúncio com os factos, e dos factos com as intervenções. A questão do Iraque ficou marcada pela falha de relação das motivações invocadas com os factos, os factos do Irão e da Coreia do Norte desafiam as motivações. A cortina da ignorância tem muitas contribuições identificáveis para a sua consistência, e essa ignorância, em muito dinamizada por decisores políticos, tem severa responsabilidade na quebra de confiança das populações nos príncipes que nos governam. E que precisam de revigorar e credibilizar os serviços de informação, e a capacidade de intervenção do aparelho diplomático, para serem dos bemvindos ao mundo do real. Não se trata de confiar, como pregou Arendt, na capacidade de implantar a verdade no domínio do discurso político interno e internacional. Nem de ter esperança de trazer a santidade para o exercício do poder, com escassos exemplos como o de Mandela. Trata-se, com maior modéstia, de conseguir que a razoabilidade seja uma directiva do diálogo, da concertação, da decisão. 0 processo político, obscurecido pela cortina de ignorância, e pela espuma do tempo, tende alarmantemente para incluir uma teoria conspirativa, composta de suspeições, descréditos, que tomam opaca a distinção entre fantasia, mentira real, e pensamento crítico sustentado. o que tudo implica exigências crescentes para a intervenção académica, mantendo clara a distinção entre teorias conspirativas e inquérito crítico. E com tal firme distinção, lidando com a precariedade do conhecimento dos factos, com o silêncio frequente dos poderes, com a cortina de ignorância tecida pela teatrologia da política, com a densidade da espuma do tempo que frequentemente vai tornando opaco o processo que define um presente sem previsão nem participação. Persistindo, todavia, em conseguir avançar para o modelo de sociedade da informação, do saber, e da sabedoria sem a qual a razoabilidade se perde. 
Tendo sempre presente que, como advertiu Max Weber, todo o saber será contestado. E por isso sempre firme na decisão de recomeçar.

\section{RESUMOS}

A complexidade crescente da rede mundial de dependências, e o tempo acelerado da mudança, ultrapassaram as capacidades, as rotinas, e a criatividade dessas estruturas, que se tinham arquitectado em tempo demorado, os Estados perderam de regra a eficácia do modelo da centralidade da direcção, e, sem grande diferença qualitativa entre poderosos e pequenos, multiplicam, por todas as áreas das competências que guardam, os centros de intervenção que se articulam em redes internacionais, sem que isso tenha necessária réplica em redes internas que mantenham a corrente da informação entre todos.

Pregadores da urgência da verdade no exercício da política como foi Ana Arendt, e da importância do diálogo como sustentam todos, dificilmente podem conciliar-se com o panorama desta época que se pretende que seja da informação e do saber, longe também da sabedoria que invocaram. Inverter o ritmo, isto é, regressar ao modelo de pensar antes de correr, exige uma profunda remodelação dos aparelhos diplomáticos, de modo que a coordenação volte a ser um valor reconhecido, não apenas pela filosofia de governo de cada Estado, também pela dos grandes espaços em que os Estados se articulam.

The growing complexity of dependencies' world net, and the quick time of change, surpassed the capacities, the routines, and the creativity of these structures, built in a lengthy time, States lost, as a rule, the efficacy of directive centrality's model, and, without any qualitative difference among powerful and small ones, multiply, in every arcas of those competences they keep, the intervention centres, which articulate themselves in international nets, without any necessary reply in internai nets that keep among everyone the information's stream.

Preachers of truth's urgency in politics' exercise, as Hannah Arendt, as well as of the significance of dialogue, as everybody maintain, can hardly conciliate themselves with this age view, which one pretends it is an age of information and knowledge, also apart from that wisdom in which they invoked. To reverse the rhythm, this is, to go back to the thinking model before running, demands a profound remodelling of the diplomatic equipments, so that coordination might be again a recognized value, not just because of each State government philosophy, but also because of that of the big spaces where States articulate themselves.

\section{ÍNDICE}

Keywords: international politics, diplomacy

Palavras-chave: política internacional, diplomacia 


\section{AUTOR}

\section{ADRIANO MOREIRA}

Presidente do Conselho Nacional de Avaliação do Ensino Superior Professor Emérito da Universidade Técnica de Lisboa.

Licenciado em Direito pela Universidade de Lisboa em 1944, ingressou no corpo docente da Escola Superior Colonial, que transformou no actual Instituto Superior de Ciências Sociais e Políticas da Universidade Técnica de Lisboa, onde autonomizou o ensino da Ciência Política, das Relações Internacionais e da Estratégia. Foi ali Director durante doze anos, e depois Presidente do Conselho Científico até à jubilação. É Doutor por aquele Instituto e Doutor em Direito pela Universidade Complutense de Madrid. Professor de Relações Internacionais, há cerca de quarenta anos, no Instituto Superior Naval de Guerra, da Escola de Comandos e Estado-maior e da Universidade Católica do Rio de Janeiro, onde organizou o Instituto de Relações Internacionais e Direito Comparado (IRICO). Professor da Universidade Católica Portuguesa. Professor Emérito da Universidade Técnica de Lisboa. Doutor Honoris Causa pelas Universidades Aberta, da Beira Interior, Manaus, Brasília, S. Paulo, Rio de Janeiro. É membro da Academia Brasileira de Letras, da Academia das Ciências de Lisboa, da Academia de Marinha, da Academia de Ciencias Morales y Politicas de Madrid e da Academia Portuguesa da História. 